\section{НОВЫЕ МЕТОДЫ \\ ИССЛЕДОВАНИЯ ПЕСЕННОЙ ТРАДИЦИИ ТУВИНЦЕВ}

\section{Аясмаа Д.-Б. Баранмаа}

Тувинский институт гуманитарных и прикладных социально-экономических исследований, Российская Федерация

Рецензия на издание: Тирон Е. Л. Песни тувинцев-тоджинцев: жанры ыр и кожамык в конще ХХ столетия / отв. ред. Г. Б. Сыченко. Новосибирск: Наука, 2018. 248 с. ISBN 978-5-02-038791-1

Монография представляет этномузыкологическое исследование, посвященное двум основным песенным жанрам тувинцев-тоджинцев - ыр и кожамык, которые проанализированы автором в сравнительном аспекте. По мнению рецензента, в работе впервые целостно и системно изучена песенная традиция тувинцев Тоджинского района Тувы, выявлены сходства и различия двух жанров на уровнях функционирования, семантики, поэтики, стихосложения, слогоритмической, темповой, ладозвукорядной и ладофункциональной организаций.

Рассматривается система интонационной культуры тувинцев-тоджинцев, в которой наиболее полно сохранившейся признана лирическая сфера, представленная традиционными песенными жанрами ыр и кожамык. Автор в работе вносит

\section{NEW METHODS FOR STUDYING THE TUVAN SONG TRADITION}

\author{
Ayasmaa D.-B. Baranmaa \\ Tuvan Institute for Humanities and \\ Applied Socioeconomic Studies, \\ Russian Federation
}

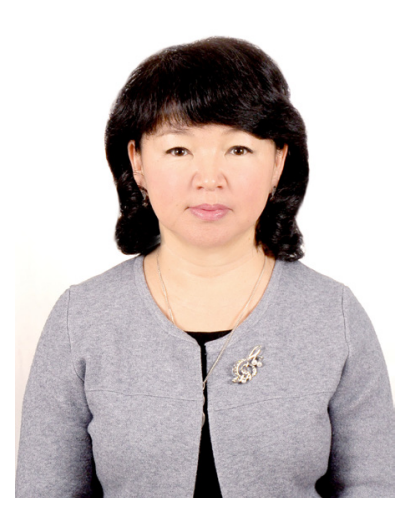

Review of: Tiron, E. L. Pesni tuvintsevtodzhintsev: zhanry yr i kozhamyk $v$ kontse XX stoletiia [Songs of the Todzhi Tuvans: the genres of yr and kozhamyk at the end of the 20th century] / ed. by G. B. Sychenko. Novosibirsk, Nauka. 248 p. ISBN 978-5-02-038791-1

The monograph is an ethnomusical study on the two main genres of Todzhi Tuvans' folk songs - yr and kozhamyk, which are analyzed in a comparative aspect. According to the reviewer, this is the first integrated and systemic study of the song tradition of the Todzhi rayon of the Republic of Tuva. The book reveals the similarities and differences between the two genres at their levels of functioning, semantics, poetics, versification, syllabic and rhythmic intonation, tempo, gamut, harmony and functional organization.

The system of intonational culture of Todzhi Tuvans receives further examination, with the lyric sphere represented by $y r$ and kozhamyk is

Баранмаа Аясмаа Данзы-Белековна - кандидат искусствоведения, ведущий научный сотрудник сектора истории и культуры Тувинского института гуманитарных и прикладных социальноэкономических исследований. Адрес: 667000, Россия, г. Кызыл, ул. Кочетова, д. 4. Тел.: +7 (39422) 2-39-36. Эл. адрес: mayasmaa@mail.ru

Baranmaa Ayasmaa Danzy-Belekovna, Candidate of Art Studies, Leading Research Fellow, History and Culture Sector, Tuvan Institute of Humanities and Applied Social and Economic Studies. Postal address: 4 Kochetova St., Kyzyl 667000 Republic of Tuva, Russian Federation). Tel.: +7 (39422) 2-39-36. E-mail: mayasmaa@mail.ru 
вклад в изучение проблемы жанра в тувинском песенном фольклоре. Опираясь на полевые исследования, Е. Л. Тирон доказывает функционирование двух основных жанров в песенной традиции тувинцев-тоджинев, а также наличие других разновидностей как өпей ыры, куда ыры, ойтулааш кожамык. В образно-тематическом содержании поэтических текстов песен, автор значительно расширяет границы образов жанра кожамык. Также автор монографии приводит сравнительный анализ временных и звуковысотных параметров организации жанров.

Особую иенность представляет собой приложение к работе, содержащее нотные расшифровки песен жанров ыр и кожамык, с текстами на тувинском и русском языках.

Книга предназначена для специалистов в области этномузыкознания и фольклористики, а также для всех интересующихся традиционной музыкальной культурой тувинцев.

Ключевые слова: тувинцы-тоджинцы; музыкальный фольклор; тувинский фольклор; тувинцы; этномузыкология; семантика; слогоритм; ладозвукоряд; рецензия found to have been almost fully preserved. The author contributes to the study of the problem of the genre in Tuvan song folklore. Based on field studies, E.L. Tiron proves the functioning of two main genres in the song tradition of Todzhi Tuvans, as well as the presence of other variations, such as lullaby (өpei yry), wedding song (kuda yry), and songs performed at the youth night parties (oitullash kozhamyk). The author significantly expands the boundaries of kozhamyk in the figurative and thematic content of the song lyrics. The author of the monograph also provides a comparative analysis of the time and pitch parameters of the organization of two genres.

Of special value is the appendix to the work containing musical transcripts of songs in the $y r$ and kozhamyk genres with lyrics transcribed in Tuvan and Russian languages.

The book is intended for specialists in the field of ethnic music and folklore studies as well as for all Tuvans who are interested in traditional musical culture.

Keywords: Tuvan-Todzha people; musical folklore; Tuvan folklore; Tuvan; ethnomusicology; semantics; syllarhythmic; tune; review
Тувинская музыкальная фольклористика пополнилась еще одним ценным научным исследованием по этномузыкологии. В 2018 г. вышла монография Е. Л. Тирон, посвященная локальным особенностям песен у тувинцев-тоджинцев (Тирон, 2018). Екатерина Леонидовна Тирон - кандидат искусствоведения, научный сотрудник сектора фольклора народов Сибири Института филологии Сибирского отделения Российской академии наук. Монография написана на основе диссертации «Песни тувинцев-тоджинцев: жанры ыр и кожамык», которую она защитила в 2015 г. (Тирон, 2015а) под руководством кандидата искусствоведения,доцента Новосибирской государственной консерватории им. М. И. Глинки Г. Б. Сыченко, которая была также руководителем дипломной работы начинающего исследователя. Издание опубликовано в рамках проекта Российского научного фонда «Текст в культуре этноса как фактор сохранения идентичности народов сибирско-дальневосточного региона» (№ 17-78-20185).

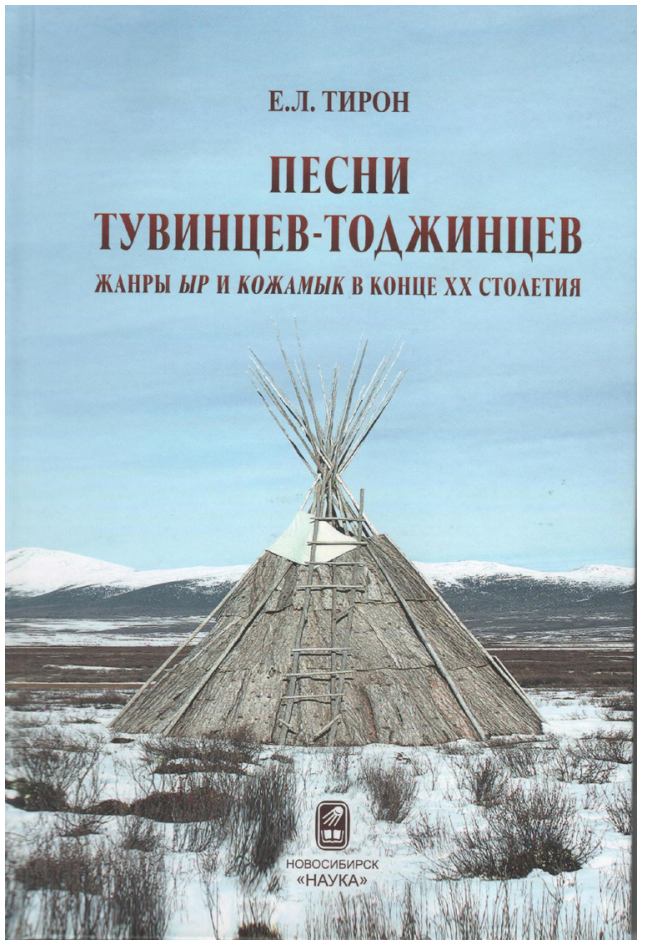


В работе впервые предпринята попытка системного сравнительного этномузыкологического изучения двух основных песенных жанров тувинцев-тоджинцев ыр (песня) и кожамык (припевка). Это один из первых опытов регионального изучения песенного жанра тувинцев, который предполагает дальнейшие исследования подобного рода и по другим песенным традициям разных районов Тувы, в которых локальные особенности выражены достаточно ярко.

Региональный аспект изучения в тувинской музыкальной науке был предпринят только в последние десятилетия. Надо отдать должное исследователям, которые планомерно занимаются фольклором сибирских народов в рамках серии «Памятники фольклора народов Сибири и Дальнего Востока». Е. Л. Тирон об этом пишет: «... на одном из совещаний Главной редколлегии серии “Памятники фольклора народов Сибири и Дальнего Востока” при обсуждении тома тувинских народных песен было принято решение о региональном изучении тувинской музыкальной культуры. В это время организуется экспедиционная работа в тувинских кожуунах, причем первыми были экспедиции в Тоджинский кожуун в 1997, 1999 и 2003 гг.» (там же: 16).

Известно, что в настоящее время по этому проекту преподавателями и сотрудниками Новосибирской государственной консерватории проведено 10 экспедиций в следующие кожууны: Тоджинский, Тере-Хольский, Сут-Хольский, Эрзинский, ТесХемский, Монгун-Тайгинский, Овюрский (там же: 16-17). Большинство экспедиций были совершены под руководством Г. Б. Сыченко. Е.Л. Тирон была участником многих из них, в том числе и тоджинских (2003, 2017) (Сыченко, Тирон, Кан-оол, 2011).

Отметим, что с этой же целью проведены три комплексные экспедиции сектора фольклора народов Сибири Института филологии СО РАН совместно с Тувинским научно-исследовательским институтом языка, литературы и истории в 1984 г. в Сут-Хольский район (рук. А. Б. Соктоев), в 2001 г. в Бай-Тайгинский район (рук. Н. А. Алексеев), в 2003 г. в Тоджинский район (там же: 16).

Монография Е. Л. Тирон (Крупич) является результатом ее многолетней работы над этой темой. Автор имеет серию статей в ведущих научных журналах и сборниках по музыкальному фольклору тувинцев-тоджинцев (Крупич, 2004, 2007; Тирон, 2013, 2014ab, 2015ab, 2016, 2017: Электр. ресурс).

Материалом исследования являются песенные образцы, записанные в ходе экспедиций в Тоджу в 1997 г. (участники: Г. Б. Сыченко, О. В. Новикова (Дондупова) и 1999 г. (участники: Г. Б. Сыченко, Н. М. Скворцова) (Тирон, 2018: 17-18). Всего записано 377 образцов; из них 85 примеров ыр и кожамык, зафиксированные от 24 информаторов. Аналитическому рассмотрению подвергнуты 28 образцов ыр, 57 кожамык, 19 колыбельных, 8 свадебных песен (там же: 23). Поэтические тексты данных коллекций были расшифрованы и переведены на русский язык известным филологом, носителем тоджинского диалекта, заслуженным деятелем науки Тувинской АССР 3. Б. Чадамба (там же: 7).

В центре внимания автора находятся песенные жанры ыр и кожамык, выявляются сходства и различия между ними на уровнях функционирования, семантики, поэтики, стихосложения, слогоритмической, темповой, ладозвукорядной и ладофункциональной организаций.

В качестве методологической основы исследования применяются методы и методики, разработанные в этнологии, филологии и музыкальной фольклористике. 
Так, при анализе вербальных текстов песен в работе использованы основные положения, разработанные в специальной литературе по тюркскому стиховедению. При рассмотрении ритмической стороны песен автор обращается к слогоритмическому методу, апробированному на материале многих музыкальных традиций России. Широко известны в музыкальной науке работы А. А. Банина, Б. Б. Ефименковой, К. В. Квитки, А. В. Рудневой, а также современных новосибирских исследователей Н. М. Кондратьевой, Г. Б. Сыченко и других. Для этого метода характерно обращение к типовым инвариантным структурам, моделирование которых производится на основе сравнения вариантов.

Новым для тувинского музыкознания является обращение к концепции интонационной культуры этноса, разработанные в трудах музыковедов Новосибирской государственной консерватории (Ю.Н.Шейкина, В.В. Мазепуса, ..Б. Сыченко, Н. М. Кондратьевой и др.) (Мазепус, 1988; Кондратьева, Мазепус, Сыченко, 1999). В изучении темпового параметра также использована новая методика, разработанная В. В. Мазепусом, Н. М. Кондратьевой и Н.С. Капицыной в опоре на концепцию «внутреннего темпа» американского этномузыковеда М. Колински, дополненная Е. Л. Тирон.

Звуковысотная организация песен опирается на разработки российской этномузыкологии (С. П. Галицкой, А. Ю. Плаховой, Н. М. Кондратьевой, В. В. Мазепуса, О.В. Новиковой, Г. Б. Сыченко и др.). Использована типология напевов, которая разрабатывается новосибирскими этномузыковедами в отношении тюркских и славянских песенных традиций (Н. В. Леонова, Г. Б. Сыченко, Е. Л. Тирон).

Работа состоит из введения, трех глав и заключения. Во введении подробно рассмотрены исследования по истории, культуре, фольклору, музыке тувинцевтоджинцев. Первая глава посвящена семантическим аспектам песенной традиции тувинцев-тоджинцев, вторая - временным параметрам организации ыр и кожамык, третья - звуковысотной организации песенной традиции.

Остановимся на основных положениях работы. В первой главе автор рассматривает интонационную культуру тувинцев-тоджинцев и выделяет несколько жанровых сфер: нарративную, паремиологическую, обрядовую, лирическую и хозяйственнопромысловую (Тирон, 2018: 27). Особый интерес представляет обрядовая сфера, в которой фигурирует термин ыры, включающая в себя шаманские камлания, шаманские песни хам ыры, заговоры чалбарыг, скотоводческие заговоры, благопожелания алгыш и йорээл, проклятия каргыш (там же: 28). Как пишет автор, в Тодже было зафиксировано семь шаманских песен хам ыры (там же: 29). Также был зафиксирован образец жанра каргыш, который был исполнен на один из типовых напевов кожамык и был определен как каргыш-кожамык (там же: 29). Наибольшее количество экспедиционной коллекции занимают жанры песенной традиции, которые отнесены к лирической сфере.

Е. Л. Тирон в работе уточняет жанровую классификацию тувинских традиционных песен на примере песенной традиции тувинцев-тоджинцев ${ }^{1}$. Как пишет автор, традиционные песни тувинцев-тоджинцев фольклорные исполнители обозначают

\footnotetext{
${ }^{1}$ Надо сказать, что впервые о двух основных жанровых группах тувинских народных песен (ырлар и кожамык) писал А. Н. Аксенов (Аксенов, 1964: 24). Позже в своем исследовании 3. К. Кыргыс
} 
двумя терминами - ыр и кожамык (там же: 22), которые интерпретируются как два основных песенных жанра. В свою очередь, эти жанры подразделяются на отдельные жанровые виды и разновидности: өпей ыры, куда ыры, ойтулааш кожамык. В результате экспедиций в разные районы Тувы выявлено, что разделение на узун ырлар, кыска ырлар в современной народной терминологии встречаются далеко не везде (Сыченко, Тирон, Кан-оол, 2011). Тоджинские информанты в конце XX в. не использовали данные термины.

Рассматривая свадебные (куда ыры) и колыбельные песни (өпей ыры), автор приходит к выводу, что свадебные песни не представляют собой отдельной жанровой разновидности, поскольку образцы подобных песен исполнялись информантами на авторскую мелодию (Тирон, 2018: 39). Колыбельные песни өпей ыры автор выделяет как отдельную жанровую традицию.

В ходе анализа текстов песен тувинцев-тоджинцев автором выявлено сходство с другими тюркскими традициями Южной Сибири, в которых также зафиксировано наличие двух основных песенных жанров. Они реализуют оппозицию «устойчивый импровизируемый тексты» (там же: 42). Для жанра ыр характерен устойчивый текст, а жанр кожамык предполагает импровизационность.

В образно-тематическом содержании кожамык автор расширяет представление об этом жанре, с которым ранее связывали только любовную и молодежную тематику ${ }^{1}$. Автор выделяет три основные так называемые сферы: этнородовые отношения этнородовых отношений, любовная сфера любовной сферы и сфера сферы природы, родных мест. Они характерны и для жанра ыр, однако в нем доминирует тема родного края, а в кожамык больше представлены любовная сфера и этнородовых отношений (там же: 54).

Систему стихосложения тоджинской песенной поэзии, слогоритмической организации ыр и кожамык Е. Л. Тирон анализирует методами, которые достаточно устоялись в филологической и музыкальной науке. Не вызывают сомнений выводы автора по этим параметрам. Автор справедливо отмечает тенденцию к индивидуализации ритма в жанре ыр (в песнях «Өдүген-Тайга», «Тоора-Хем», «Чашпы-Хем», «Тожама») и стремление к типизации ритма в кожамык.

В работе есть отдельный раздел, рассматривающий темп как жанрово-дифференцирующий маркер песенной традиции тоджинцев. Е. Л. Тирон обращается к методологии темпового анализа, разработанной Н. М. Кондратьевой и Н. С. Капицыной на основе категории «внутреннего темпа» американского этномузыковеда М. Колински (Kolinski, 1959), учитывающей не только продолжительность, но и архитектонический темп и строковую плотность (понятия предложены вышеназванными авторами) (Капицына, Кондратьева, 2004)). Автор обращается к понятию метрономического темпа, который рассчитывается по определенной формуле. Приведены способы

предложила разделение на три жанровые группы: узун ырлар (протяжные песни), кыска ырлар (короткие песни) и кожамык (припевки) (Кыргыс, 1992:63-64). Кжанровой классификации тувинских традиционных песен обращались и другие исследователи Н. М. Кондратьева, О.В.Новикова, А. Х. Кан-оол и автор данной рецензии.

${ }^{1}$ Так, А. Н. Аксенов отмечал, что для поэтических текстов жанра кожамык характерна любовная и молодежная тематика (Аксенов, 1964: 25). 3. К. Кыргыс по содержанию поэтических текстов относит кожамык к роду любовной лирики (Кыргыс, 1992: 64). 
вычисления, таблицы, графические рисунки. Однако, в конечном итоге выводы по этому разделу, на мой взгляд, не совсем убедительны. Возможно, эти вычисления сделаны автором в виде эксперимента.

Как указывалось, отдельная глава исследования посвящена звуковысотной организации песенной традиции тувинцев-тоджинцев. В мелодическом отношении жанр ыр характеризуется своим неповторимым мелодическим типом, а жанр кожамык исполняются на ограниченное число типовых напевов. Автор справедливо замечает, что наиболее стабильным параметром организации типовых напевов является слогоритмический уровень, более подвижным - звуковысотный (там же: 103). Е. Л. Тирон выделила всего 19 типовых напевов в данном жанре. Интересна гипотеза автора о существовании в прошлом закрепленных за определенными родами типовых напевов кожамык, поскольку, по мнению информаторов, напевы принадлежали какому-либо роду, например роду Кол или Ак-Чооду и т. д. (там же: 109).

При анализе звуковысотной организации автор использует метод транспонирования звукоряда на основе сравнения интервального состава, который был использован еще А.Н. Аксеновым (Аксенов, 1964: 51). В результате выстраивается единые суммарные звукоряды для жанра ыр и кожамык в отдельности. Использован статистический метод, для определения частоты использования каждого звука. Выявляются функционально значимые (опорные) ступени - ладовая функциональность. В песнях тувинцев-тоджинцев также отмечен приоритет ангемитонной пентатоники как ладовой организации (Аксенов, 1964; Сузукей, 1989; Кыргыс, 1992; Монгуш, 2013).

При больших достоинствах данного раздела исследования, на мой взгляд, не хватило интонационного анализа конкретных песенных образцов. За схемами и таблицами, которые, несомненно, нужны, не чувствуется «живых» песен, характерных мелодических оборотов, типичных интонаций именно для традиции тоджинских тувинцев.

Таким образом, в монографии Е.Л.Тирон впервые предпринята попытка системного этномузыкологического изучения песенной традиции тувинцев-тоджинцев (жанров ыр и кожамык), с опорой на труды российских исследователей по этнологии, филологии, музыкальной фольклористике, а также работы новосибирских музыковедов (В. В. Мазепуса, Н. М. Кондратьевой, Г. Б. Сыченко, О. В. Новиковой, Н. М. Скворцовой и др.). Песенная традиция рассмотрена в сравнительном ключе с точки зрения семантики, временных и звуковысотных параметров. Работа содержит большое приложение с нотными расшифровками традиционных песен жанров ыр и кожамык тоджинских тувинцев с текстами на русском и тувинском языках.

Нельзя не отметить высокое качество вербальных и нотных текстов, а также интересное оформление работы. Действительно была проведена очень плодотворная совместная работа музыковедов (научного руководителя Г.Б. Сыченко, автора рецензируемой монографии Е.Л.Тирон и участников экспедиции) и филолога, известного исследователя тувинского языка З. Б. Чадамба. Благодаря этому работа имеет большую практическую значимость. Несомненно, монография вносит большой вклад в развитие тувинской, шире сибирской этномузыкологии и имеет важное значение для сохранения угасающей песенной традиции тувинцев-тоджинцев. 


\section{СПИСОК ЛИТЕРАТУРЫ}

Аксенов, А. Н. (1964) Тувинская народная музыка / под ред. и с предисловием Е. В. Гиппиуса. М. : Музыка. 238 с.

Капицына, Н. С., Кондратьева, Н. М. (2004) Темповые характеристики как жанродифференцирующие признаки песенной традиции обских чатов // Народная культура Сибири: материалы XIII науч. семинара Сибирского регионального вузовского центра по фольклору / отв. ред. Т. Г. Леонова. Омск : Изд-во ОмГПУ. 300 с. С. 71-73.

Кондратьева, Н. М., Мазепус, В. В., Сыченко, Г. Б. (1999) К теории интонационных культур: интонационная культура теленгитов // Вопросы музыкознания : сборник статей / сост. Б. А. Шиндин. Новосибирск : Изд. НГК. 332 с. С. 212-225.

Кыргыс, 3. К. (1992) Песенная культура тувинского народа. Кызыл : Тувинское книжное издательство. 144 с.

Крупич, Е. Л. (2004) Этнокультурный контекст песенной традиции тувинцевтоджинцев // Народная культура Сибири: материалы XIII науч. семинара Сибирского регионального вузовского центра по фольклору / отв. ред. Т. Г. Леонова. Омск : Изд-во ОмГПУ. 300 с. С. $96-100$.

Крупич,Е.Л.(2007) Образно-тематическая характеристика жанра кожамык тувинцевтоджинцев // Мельниковские чтения: материалы второй региональной науч.-практ. конф. / отв. ред. Т. Г. Леонова. Новосибирск : Изд-во «Амфора». 376 с. С. 303-308.

Мазепус, В. В. (1988) Культурный контекст этномузыкальных систем // Музыкальная этнография Северной Азии: сборник статей / отв. ред. Ю. И. Шейкин. Новосибирск : Изд. НГК. 216 с. С. $28-44$.

Монгуш, А. Д.-Б. (2013) Тувинский песенный фольклор : ладозвукорядный аспект. Абакан : Кооператив Журналист. 200 с.

Сузукей, В. Ю. (1989) Проблема лада в тувинской народной музыке: (теоретические и практические аспекты). Кызыл : Тувинское книжное издательство. 66 с.

Сыченко, Г. Б., Тирон, Е. Л., Кан-оол, А. Х. (2011) Результаты полевых и научных исследований Новосибирской консерватории в Республике Тыва (1997-2009гг.) // От конгресса к конгрессу: материалы Второго Всерос. Конгресса фольклористов. Т. 3./ отв. ред. А. С. Каргин. М. : Гос. республиканский центр русского фольклора. 456 с. C. 281-299.

Тирон, Е. Л. (2013) Особенности стихосложения песен тувинцев-тоджинцев // Сибирский филологический журнал. № 2. С. 48-55.

Тирон, Е. Л. (2014а) Жанровая дифференциация лирических песен тувинцевтоджинцев // Музыковедение. № 5. С. 52-58.

Тирон, Е. Л. (2014b) Фольклор тувинцев-тоджинцев: история собирания и публикации // Историческая этнография: сб. науч. ст. / под ред. И. И. Верняева, А. Г. Новожилова. СПб. Вып. 5. С. 182-185.

Тирон, Е. Л. (2015а) Песни тувинцев-тоджинцев: жанры ыр и кожамык : дис. ... канд. искусствоведения. Новосибирск. 270 c.

Тирон, Е. Л. (2015b) Типовые напевы кожамык тувинцев-тоджинцев // Вестник Кемеровского государственного университета культуры и искусств. № 31. С. 20-26.

Тирон, Е. Л. (2016) Ладозвукорядная организация кожамык тувинцев-тоджинцев // Вестник музыкальной науки. № 1 (11). С. 38-44. 
Тирон, Е. Л. (2017) Песенный фольклор тувинцев-тоджинцев: собирание, публикации, исследования [Электронный ресурс] // Новые исследования Тувы. № 2. URL: https://nit.tuva.asia/nit/article/view/711 (дата обращения: 15.08.2018). DOI: 10.25178/ nit.2017.2.15

Тирон, Е. Л. (2018) Песни тувинцев-тоджинцев: жанры ыр и кожамык в конце ХХ столетия / отв. ред. Г. Б. Сыченко. Новосибирск : Наука. 248 с.

Kolinski, M. (1959) The evaluation of tempo // Ethnomusicology. Vol. 3. № 2. P. 45-57. DOI: $10.2307 / 924285$

Дата поступления: 10.10.2018 г.

\section{REFERENCES}

Aksenov, A. N. (1964) Tuvinskaia narodnaia muzyka [Tuvan folk music] / ed. by E. V. Gippius. Moscow, Muzyka. 238 p. (In Russ.).

Kapicyna, N. S. and Kondrat'eva, N. M. (2004) Tempovye kharakteristiki kak zhanrodifferentsiruiushchie priznaki pesennoi traditsii obskikh chatov [Tempo features as genre features of the Ob chat]. In: Narodnaia kul'tura Sibiri: materialy XIII nauch. seminara Sibirskogo regional'nogo vuzovskogo centra po fol'kloru [The folk culture of Siberia: Proceedings of 13th research seminar of the Siberian Regional University Center for Folklore] / ed. by T. G. Leonova. Omsk, OmGPU Publ. 300 p. Pp. 71-73. (In Russ.).

Kondrat'eva, N. M., Mazepus and V. V., Sychenko, G. B. (1999) K teorii intonatsionnykh kul'tur: intonatsionnaia kul'tura telengitov [On the theory of intonation cultures: intonation culture of Telengits]. In: Voprosy muzykoznaniia [Issues of musicology] : a collection of articles / ed. by. B. A. Shindin. Novosibirsk, NGK Publ. 332 p. Pp. 212-225. (In Russ.).

Kyrgys, Z. K. (1992) Pesennaia kul'tura tuvinskogo naroda [Song culture of the Tuvan people]. Kyzyl, Tuvan book publisher. 144 p. (In Russ.).

Krupich, E. L. (2004) Etnokul'turnyi kontekst pesennoi traditsii tuvintsev-todzhintsev [Ethno-cultural context of the song traditionsof the Todzhi Tuvans]. In: Narodnaia kul'tura Sibiri: materialy XIII nauch. seminara Sibirskogo regional'nogo vuzovskogo centra po fol'kloru [The folk culture of Siberia: Proceedings of 13th research seminar of the Siberian Regional University Center for Folklore] / ed. by T. G. Leonova. Omsk, OmGPU Publ. 300 p. Pp. 96-100. (In Russ.).

Krupich, E. L. (2007) Obrazno-tematicheskaia kharakteristika zhanra kozhamyk tuvintsev-todzhintsev [Imagery and thematic characteristics of the kozhamyk genre of Todzhi Tuvans]. In: Mel'nikovskie chteniia: materialy vtoroi regional'noi nauch.-prakt. konf [Melnikov readings: Proceedings of the 2nd regional research and practical conference] / ed. by T. G. Leonova. Novosibirsk, Amfora Publ. 376 p. Pp. 303-308. (In Russ.).

Mazepus, V. V. (1988) Kul'turnyi kontekst etnomuzykal'nykh sistem [The cultural context of ethnomusical systems]. In: Muzykal'naia etnografia Severnoi Azii [Musical ethnography of Northern Asia] : a collection of articles / ed. by Ju. I. Sheikin. Novosibirsk, NGK Publ. 216 p. Pp. 28-44. (In Russ.).

Mongush, A. D.-B. (2013) Tuvinskii pesennyi fol'klor: ladozvukoriadnyi aspect [Tuvan folk songs: aspects of gamut and harmony]. Abakan, Kooperativ Zhurnalist. 200 p. (In Russ.).

Suzukei, V. Iu. (1989) Problema lada v tuvinskoi narodnoi muzyke: (teoreticheskie i prakticheskie aspekty) [The issue of harmony in Tuvan folk music: theoretical and practical aspects]. Kyzyl, Tuvan book publ. 66 p. (In Russ.).

Sychenko, G. B., Tiron E. L. and Kan-ool, A. H. (2011) Rezul'taty polevykh i nauchnykh 
issledovanii Novosibirskoi konservatorii v Respublike Tyva (1997-2009gg.) [Results of field studies and research of the Novosibirsk Conservatory in the Republic of Tuva (1997-2009)]. In: Ot kongressa k kongressu: materialy Vtorogo Vseros. Kongressa fol'kloristov [From Congress to Congress: Proceedings of the 2nd All-Russia Congress of folklorists], vol. 3. / ed. by A. S. Kargin. Moscow, Gos. respublikanskii centr russkogo fol'klora. 456 p. Pp. 281-299. (In Russ.).

Tiron, E. L. (2013) Osobennosti stihoslozheniia pesen tuvintsev-todzhintsev [Features of the poetry of the songs of Todzhi Tuvans]. Sibirskii filologicheskii zhurnal, no 2, pp. 48-55. (In Russ.).

Tiron, E. L. (2014a) Zhanrovaia differentsiatsiia liricheskikh pesen tuvintsev-todzhintsev [Genre differentiation of lyrical songs of Todzhi Tuvans]. Muzykovedenie, no. 5, pp. 52-58. (In Russ.).

Tiron, E. L. (2014b) Fol'klor tuvintsev-todzhintsev: istoriia sobiraniia i publikatsii [Folklore of Todzhi Tuvans: the history of collecting and publishing]. In: Istoricheskaia etnografia [Historical Ethnography]: a collection of articles / ed. by I. I. Verniaeva and A. G. Novozhilova. St. Petersburg. Vol. 5. Pp. 182-185. (In Russ.).

Tiron, E. L. (2015a) Pesni tuvintsev-todzhintsev: zhanry yr i kozhamyk [Songs of the Todzhi Tuvans: the genres of yr and kozhamyk] : Diss. ... Candidate of Arts. Novosibirsk. 270 p. (In Russ.).

Tiron, E. L. (2015b) Tipovye napevy kozhamyk tuvintsev-todzhintsev [The common tunes of Todzhi Tuvans' kozhamyk]. In: Vestnik Kemerovskogo gosudarstvennogo universiteta kul'tury i iskusstv, no. 31, pp. 20-26. (In Russ.).

Tiron, E. L. (2016) Ladozvukoriadnaia organizatsiia kozhamyk tuvintsev-todzhintsev [Gamut and harmony in the system of kozhamyk by Todzhi Tuvans]. Vestnik muzykal'noi nauki, no. 1 (11), pp. 38-44. (In Russ.).

Tiron, E. L. (2017) Pesennyi fol'klor tuvintsev-todzhintsev: sobiranie, publikatsii, issledovaniia [Song folklore of Todzhi Tuvans: collection, publication, research]. The New Research of Tuva, no. 2 [online] Available at: https://nit.tuva.asia/nit/article/view/711 (access date: 15.08.2018). DOI: $10.25178 /$ nit.2017.2.15

Tiron, E. L. (2018) Pesni tuvintsev-todzhintsev: zhanry yr i kozhamyk $v$ kontse XX stoletiia [Songs of the Todzhi Tuvans: the genres of yr and kozhamyk at the end of the 20th century] / ed. by G. B. Sychenko. Novosibirsk, Nauka. 248 p. (In Russ.).

Kolinski, M. (1959) The evaluation of tempo. Ethnomusicology, vol. 3, no. 2, pp. 45-57. DOI: $10.2307 / 924285$

Submission date: 10.10 .2018$.

\section{Для циитирования:}

Баранмаа А. Д.-Б. Новые методы исследования песенной традиции тувинцев [Электронный ресурс] // Новые исследования Тувы. 2018, № 4. URL: https://nit.tuva. asia/nit/article/view/818 (дата обращения: дд.мм.гг.). DOI: 10.25178/nit.2018.4.15

\section{For citation:}

Baranmaa A. D.-B. New methods for studying the Tuvan song tradition. The New Research of Tuva, 2018, no. 4 [on-line] Available at: https://nit.tuva.asia/nit/article/view/818 (accessed:...). DOI: 10.25178/nit.2018.4.15 